\title{
Supposed pronounced ecophenotypy in foraminifera
}

\author{
J.R. HAYNES \\ Institute of Earth Studies \\ University College of Wales \\ Aberystwyth \\ Dyfed SY23 3DB, Wales, UK.
}

\begin{abstract}
The use of the term ecophenotype in the literature on foraminifera is confused and misleading. The results of tank experiments, held to demonstrate that extensive morphological variation occurs, beyond what is normally regarded as specific, and is environmentally determined, can be otherwise explained. The suggestion that the Ammonia beccarii group should be reduced to three 'forms' and that even the type is an ecophenotype should therefore be treated with reserve. J.Micropalaeontol. 11(1): 59-63, June 1992
\end{abstract}

\section{INTRODUCTION}

An ecological geneticist, straying into the field of foraminiferology, would almost certainly be surprised by the spectacle of nineteenth century battles still being fought between 'lumpers' and 'splitters'; the lumpers taking the moral high ground with appeals to the gurus of the early English School (like H.B. Brady) and shrill cries of 'nomenclatural chaos', and 'this madness must stop', (Parker, 1962; Boltovskoy, 1965; Poag, 1978; Walton \& Sloan, 1990). The geneticist might also have reasonable grounds to suppose that one could still discern the flags of neolamarckism and even, 'expediency', flying in the murk.

The ecological geneticist would undoubtedly be surprised by the denial of genetic variation and subspecies in morphologically variable cosmopolitan species and species groups of foraminifera and the asserted ubiquity of 'ecophenotypes'. ThusSchnitker (1974, p.222, col. 2), concludes that Ammonia beccarii is, 'the only valid species', encountered along the North American east coast, and that, 'the great morphological variability displayed by this species is probably due to environmental factors. The six 'species'... placed in synonymy represent a recognition of ecophenotypes...'. Similarly, Poag (1978, p.402, col. 1) states, 'it seems clear that only a few (perhaps just one) true species of Ammonia live in modern western Atlantic estuaries. The influence of environmental gradients and fluctuations have produced, on the other hand, numerous ecophenotypes'. It is also clear from his introduction (p.395, cols 1 \& 2) that he considers that the discovery of 'paired foraminiferal ecophenotypes' may explain the 'minute and subtle morphologic changes among fossil lineages' for which hitherto, the 'reasons have not been understood'. Not only do Walton \& Sloan (1990) synonymise all modern Ammonia species under $A$. beccarii as three forms, they suggest, "forma beccarii may also be an ecophenotype', (Abstract, line 6). As this is the type it would effectively return Ammonia to Rotalia, despite its different internal characters (see Haynes \& Whittaker, 1990).

In case it be thought that I have been unfairly selective in quoting these authors, the reader is advised to consider these quotes in the context of the introductory remarks and conclusions in their papers, I think it will be seen that the emphasis upon ecophenotypes underpins a research strategy strongly directed towards the reduction of what is felt to be unnecessary splitting. As Walton \& Sloan say (1990, p.130, col.2, p. 131, col. 1) 'It is difficult... not to conclude that many species and subspecies of foraminifera described in the literature are environmentally controlled, phenotypic variants of single species'.

This enthusiasm for ecophenotypes has arisen largely from Schnitker's tank experiments upon Ammonia tepida (Cushman) published in 1974 in a paper that has been widely quoted. The species was collected from five different sub-tidal, near-shore localities along the east coast of the U.S.A. from Maine to N. Carolina. Experiments were made to determine both the minimum temperature at which mobility occurs and the minimum temperature at which reproduction takes place. The results suggested that the local populations are adjusted to the different regional temperature regimes but that acclimatisation possibly takes place at, or shortly after, reproduction. Further, the appearance of a number of morphological variants during the course of the experiments, in what were regarded as cloned cultures, led him to lump all the seven species of Ammonia previously recognised along the east coast of the U.S.A. as ecophenotypes of $A$. beccarii (Linné).

The apparent success of these experiments, held to 'prove beyond doubt' (Poag, 1978, p.401, col. 2, para. 1), and to provide, 'the most convincing evidence', (Walton \& Sloan, 1990 , p.130, col. 1, para. 3) that the morphological variation in the Ammonia beccarii group is ecophenotypic and can occur within a single clonal population, has encouraged the continuance of the nineteenth century idea of the plasticity of foraminiferal species and its extension to other variable, late Quaternary species such as the Elphidium excavatum plexus (Feyling-Hanssen, 1972; Hansen \& Lykke-Anderson, 1976; Miller et al. 1982). Just how influential these experiments have been is shown by the almost obligatory inclusion of a section on ecophenotypes in John Murray's book on Recent foraminiferal distribution (1991).

\section{ECOPHENOTYPY IN GENERAL}

In contrast to this emphasis upon ecophenotypy in foraminifera the treatment of this phenomenon is rather more muted in general works on ecological genetics. The term 'ecophenotype' (see definition below) was not used in the famous textbook by Ford (1975) a notable pioneer in the subject. In cases where the expression of the genotype can be altered by environmental 
influences he used the term, genetic plasticity. In the textbook by Merrell (1981) the term is subsumed under 'developmental adaptation' which (although itself under genetic control) may beflexible enough to allow different phenotypes better adapted to different environmental conditions, e.g. alpine dwarfing. This kind of developmental flexibility is more common in plants because development in animals tends to be more channelled. Moreover, as Merrell notes (p.118, para. 3) 'ordinarily, it is relatively simple to distinguish between developmental and environmental polymorphism... and genetic polymorphism...'. This is borne out by the great success of selective breeding of plants and animals by man. Again, within the human species differences in size, skin colour, hair type and blood groups can usually be distinguished from environmental effects. Similarly, the experienced taxonomist will not normally be misled by the effects of crowding, stunting, adaptation to substrate and malformation due to pollutants well known in groups such as oysters and foraminifera. In these cases the use of this term will hardly be necessary. (In line with Merrell, the term is used only in passing in the book on genetics by Levinton (1988) and it is not in his subject index or glossary).

Difficulties will arise in those rarer cases which involve more than a simple adaptive response and can be regarded as satisfying a strict definition of ecophenotypy (included under 'genetic plasticity' by Ford, see below), i.e. variation in the adult, not necessarily adaptive, resulting from the action of a specific environmental factor on the juvenile, such as the colour changes in adult insects which result from the subjection of the pupae to temperatures beyond the normal range. How far do the results of Schnitker's experiments satisfy either of those criteria?

\section{EVALUATIONOF SCHNITKER'S TANKEXPERIMENTS.}

Several young adults (15 to 20-chambered individuals corresponding to the material studied by Bradshaw (1957. 1961 ) in his pioneer work on Ammonia tepida) from each of the five field collections were maintained at $23^{\circ} \mathrm{C}$ and inspected daily for reproduction. After reproduction, the first brood was transferred to an incubation chamber and held at $12-14^{\circ} \mathrm{C}$, permitting slow growth until 10 chambers had been added. The broods were then transferred and held at $8^{\circ} \mathrm{C}$, at which temperature, locomotion, feeding and growth ceased, until sufficient 10-chambered specimens were obtained for the temperature experiments. These involved raising the temperatures $1^{\circ} \mathrm{C}$ per week and noting the time of onset of locomotion, feeding and reproduction and were repeated through nine generations (over $2^{t} / 2$ years).

The culture from Maine was the first to resume activity and showed the highest growth rate, whereas the cultures from $\mathrm{N}$. Caroline were the last, the other cultures occupied intermediate positions. On this basis Schnitker decided, 'Apparently $A$. tepida is represented along the eastern seaboard of the United States by a series of gradually changing contiguous populations, or, in short, a physiological cline', (p.221, col. 1, para. 1). He went on to say that, as was noted by Bradshaw (1961), previous temperature history did not affect the results and, therefore, that the different temperature requirements reflect innate differences, concluding (p.221, col. 2, para. 2) that $A$. tepida is a eurythermal species successful over a wide range of conditions with local populations, exhibiting narrow temperature differences produced by 'selective pressure', i.e. ecotypes (see definition below). There will be no quarrel with this general conclusion which, indeed, is expected from the use of the term ecotype in the title of the paper (but not used thereafter).

However, the experiments also showed that temperature requirements shifted slightly with each successive reproduction, the lower reproductive limit by as much as $3^{\circ} \mathrm{C}$ over nine successive generations, extrapolation of the graphs indicating a common mean reproductive temperature of $22.5^{\circ} \mathrm{C}$ after 13 or 14 generations. As it was assumed that the cultures represented clones, this led Schnitker to claim in his Conclusion (p.222, col. 2) that the different temperature requirements of the local populations are not genetically fixed and represent local acclimatisation of a single (genetically) unified population (thus contradicting statements made in the Discussion and the title of the paper). Apart from the fact that the experiments were not carried through to the required number of generations to prove this postulation and the curve for Maine could be redrawn to show a flattening out, there must be legitimate doubt that true clones were established. The reproduction cycle of Ammonia tepida (or beccarii) is unknown. Bradshaw (1957, p.1139, col. 1, para. 2) admitted that, 'no good evidence had been seen of a dimorphic alternation of generations', and assumed he was dealing with the megalospheric, A form (i.e. the haploid sexual form). In order to, 'minimise the possible effect of any hereditary differences', he selected groups of young foraminifera, in a random manner from the same mass culture', for his experiments (p.1140, col. 1, para. 2). Schnitker does not discuss this problem but states (p.221, col. 1, para. 2) that all reproduction recorded was asexual. Even if this was actually the case (serial mitosis in the $A$ form) with no production of sexual gametes during the whole $2^{1} / 2$ years, the fact that 'several' individuals from each field collection (rather than one parent from each) were cultured, and all the ensuing broods transferred for experiment, means that it is unlikely that a pure strain was established. There is also the problem that not all the cultures were agnotobiotic and the possibility of the transfer of zygotes. It could be argued that acclimatisation to different temperatures actually involved selection.

The most striking result of the experiments was the appearance of morphological variants in the cultures of $A$. trepida. Considering the importance which has been attached to these supposed ecophenotypes the information given is meagre. We are not told when, or in which broods they appeared, or in what proportions, except in the case of $A$. sobrina which appeared in F3 of the Delaware stock, after the culture was left on a shelf in near darkness for three months at room temperatures of $20^{\prime \prime} \mathrm{C}$ to $25^{\prime \prime} \mathrm{C}$. The 'ecophenotypes' cannot, therefore, be related to the temperature experiments or to the physiological cline (or series of acclimatised local populations). No evidence is given to back up the claim in the Conclusions (p.222, col. 2, last para.), that, 'The great morphological variability displayed by this species (A. beccarii s. 1.) is probably due to environmental factors'. It is significant that the 'ecophenotypes' match all the species common in the original field localities. This is a remarkable coincidence if this 
is a case of ecophenotypy, narrowly defined as non-genetic variation (not necessarily adaptive) induced by subjection of the juvenile to an environmental factor (in this case temperature) outside the normal range. On the other hand, it can be taken as crucial evidence that a pure clone was not achieved.

\section{DISCUSSION}

Because of their impact over the last two decades, Schnitker's paper and remarkable results deserveclosescrutiny. Ironically, although the bulk of the paper is concerned with experiments devised to test the temperature dependence of a series of possible ecotypes (as shown by his title) it is the last brief section on the morphological 'ecophenotypes', added more as an addendum and poorly documented, which has carried the day. However, the results are ambiguous and the conclusions ambivalent. This has led workers, eager to apply the idea of ecophenotypy, into serious difficulties. For example although Schnitker did not demonstrate any connection between the morphological variants and type of temperature treatment and the 'physiological cline', nor establish any morphological clines, Poag applied the idea to morphological clines he recognised in Gulf Coast estuaries, (1978, p.397, col. 1) 'many of the morphological characteristics of a given species vary as clines from one dominant ecophenotype to the other across (sic) the salinity gradients'. Apart from the difficulty of seeing how ecophenotypy could produce morphological continua along the salinity and temperature gradients (salinity was held constant in Schnitker's experiments), it seems certain that without the influence of Schnitker's paper, Poag would have referred his dominant forms to ecotypes (along a stepped cline - see definition below).

Further, although Schnitker concluded (Conclusions, p.222, last para.) 'the recognition of ecophenotypes is of great practical significance in ecological and paleoecological work', this (perhaps unsurprisingly, in view of the difficulties), has not proved to be so in practice because it has simply led to indiscriminate lumping. This is shown by the summary of benthonic foraminiferal ecology given in Murray's new book (1991) in which Ammonia beccarii is given a world-wide low to mid-latitude range, with no useful ecophenotypes being recognised.

The effect of the extension of the idea of pronounced ecophenotypy to the Elphidium excavatum group by Feyling-Hanssen, with reduction of the main members, selseyensis and clavatum to forms, has been rather more complicated. One interesting feature, from the historical point of view, is that this preceded the publication of Schnitker's work which therefore might be said to represent a paper 'waiting to be written' in sympathy with the prevailing ideology. Haynes, however $(1973,1981)$ considered selseyensis and clavatum worthy of specific, or at least sub-specific rank. Wilkinson (1979) regarded the members as sub-species of Elphidium clavatum (which offends the rules of the ICZN, because selseyense has clear priority). In contrast, the idea of ecophenotypy was strongly endorsed by Miller et al. 1982 who regarded the group as 'taxonomically identical' but useful 'because indicative of environmental conditions'. Unfortunately, despite the excellent figures of Feyling-Hanssen and Miller et al. and, perhaps, inevitably, considering that the forms are regarded as taxonomically (i.e. genetically) identical, workers on the eastern seaboard of the U.S.A. have tended to lump the members of this group, usually under clavatum or incertum. This has confused the taxonomy and ecological relationships and made it impossible for Murray to establish consistent records. Thus, on the Atlantic Seaboard of $N$. America, E. excavatum "forma" clavatum is plotted as far south as PimlicoSound, N. Carolina (Fig. 6.3, tab.6.16), and regarded as broadly temperature tolerant $\left(-1^{\circ}\right.$ to $\left.26^{\circ} \mathrm{C}\right)$ with no major environmental control (Tab. 6.13). However, in the Baltic, $E$. clavatum is distinguished at species level from E. excavatum and considered characteristic of the saline deep-water layer (p.142, col. 2, line 4). On p.166, col. 1, line 4, the E. clavatum association is considered the only one on the European Seaboard 'confined to the northernmost latitudes' (Fig.9.5). Its distribution in the Pacific is similar (p.248, tab. 14.7) where the temperature range is given as $4-13^{\circ} \mathrm{C}$. It is also one of the ten associations recognised in the Arctic (p.282, tab. 17.3), temperature range -2 to $10^{\circ} \mathrm{C}$. These high latitude records are consistent with its range in the late-glacial of N.W. Europe and strongly suggest that the anomalous range on the Atlantic Seaboard of North America results from the confusion about ecophenotypes.

It would be inadvisable to gallop into the lists brandishing a banner emblazoned with manifest 'truths', in the manner of Walton \& Sloan (1990, p.146, col.2), but it is worth pointing out that gel electrophoresis (although it underestimates it) has confirmed 'that natural populations of most plant and animal species are genetically highly variable', (Ward \& Galleguillos, 1978). Significantly, Selander \& Kaufman (1973) found that protein polymorphism, as a measure of genetic variability, is greater in small invertebrates and suggested it represented adaptation to a variety of sub-niches in patchy environments. Further, a number of species of Vargula, the bioluminescent ostracod adapted to different, shallow marine subniches and, 'differing in few morphological characters but distinctive in diet, habitat and bioluminescent patterns', show 'noticeable differences between the karyotypes' (Moguilevsky, 1990). That similar genetic variability is likely to occur within and between sibling species of foraminifera is suggested by the preliminary work of Robbins \& Healy-Williams (1991) using oxygen and carbon isotope data and amino-acid assay.

We have, therefore, no reason to suppose that foraminifera inhabit 'another country' where things are done differently, apart from the idea received from the early English School that they are a primitive, plastic group. In fact, Patellina has some three times as many chromosomes ( 24 in Patellina corrugata, see Grell, 1973, tab. 1) as Drosophila. This is not to say there may not be peculiarities. Patellina corrugata could be polyploid and doubling of the chromosomes by this means might be more common in foraminifera (and other protists) than in the Animal Kingdom. Again, simplification of morphology and reduction in chamber numbers is exhibited by many lines in the foraminifera and may be related to apogamy and reduction in genetic variability. However, in the case of successful species groups, actively expanding their range in the late Quaternary, like Ammonia ex. gr. beccarii and Elphidium ex. gr. excavatum, it seems a reasonable expectation that cytological work will 
eventually demonstrate a continuum from genetic polymorphism within single populations ('forms') through ecotypes to subspecies and polytypic species, as in many plants and animals. The ready acceptance of the results of the tank experiments as proof of a high degree of ecophenotypy in foraminifera stem, perhaps, not only from the persistent belief in their particular plasticity (a Kuhnian paradigm) but also from social pressures since World War II, leading to an emphasis upon environmental determinism and a polarisation of attitudes (a period when adherents of the 'hereditarian' camp have been literally driven off university campuses by the battalions of the Politically Correct). For instance, Johnson (1981) in his attempt to detect ecophenotypic variation in Jurassic scallops, suggested that 'The village blacksmith, he of the bulging biceps and calloused hands, and the weedy, book-worming academic', were 'obviously to some extent' examples of ecophenotypes. However, they are, better, examples of human polymorphism and selection. If identical-twins were subjected to these different lifestyles it is unlikely they would show more than a difference in musculature. Further, although he ascribed his failure to demonstrate that local populations of Radulopecten vagans were ecophenotypes, to ecophenotypic variation within the populations, it seems reasonable to suspect that genetic factors and selection are also involved in the convergence of means for striae number and shell height shown by the adults from the different locations.

Another consequence of an undue emphasis upon environmental determinism, as a cause of variation is the tendency of some workers to treat species as individual 'entities'. Darwin briefly flirted with this idea, and the possibility that a species might have a life-span, while off Chile on the Beagle, as a solution to the problem of extinctions (see Desmond \& Moore, 1991, p.159), but soon abandoned it. What we have to remember is that only individual organisms are entities whereas populations and species are statistical abstractions. We shall then avoid the essentialist trap of pursuing the 'real' species while discounting intra-specific variation because it is regarded as not being part of the real stuff of evolution; attention then being switched to the level of 'species selection'. Although macro-evolutionary events, especially mass extinctions, are extremely important in clearing the stage for a new production of nature, without microevolution it would be Hamlet without the Prince of Denmark.

\section{CONCLUSIONS}

Tank experiments on populations of Ammonia tepida, apparently adapted to local temperature regimes, have been held to demonstrate both ecophenotypy in the wide-sense (acclimatisation of successive generations to increased temperatures) and ecophenotypy in the narrow sense (spontaneous appearance of morphological variants as a result of subjection of the juveniles to temperatures outside the normal range). However, serious doubts must be entertained as to whether pure clones were established in the first place, and the fact that all the variants can be matched at the original collecting sites suggests they were not. This seriously undermines the suggestion that most, or all, the hitherto recognised species and subspecies should be grouped as a limited number of 'forms' under Ammonia beccarii, especially as this term in the strict sense refers to variants within a population: the Ammonia beccarii group in the late Quaternary cannot be considered a single population. Far from providing a remedy for 'nomenclatural chaos' it has only madeconfusion worse, especially in the extension of the idea to the Elphidium excavatum group. The further suggestion, that even Ammonia beccarii may be an ecophenotype, must be rejected because Rotalia trochidiformis differs fundamentally in internal structure. Clearly, more work in ecology, genetics, stratigraphy and systematics is required, keeping in mind that lumpers are not necessarily more infallible than splitters' (Merrill, 1981, p.361) and that infra-specific distinctions are required for detailed charting of evolution.

\section{GLOSSARY}

As there appears to be some confusion about the use of particular terms (and my post-graduate students, on questioning, turned out to be uncertain of the difference between ecotypes and ecophenotypes) it is thought helpful to provide definitions from Lincoln \& Boxshall (1987) together with original sources.

Genotype (introduced by Johannson, 1909 at the same time as gene and phenotype) - 'The hereditary or genetic constitution of a cell, usually referring only to the nuclear material'.

Phenotype - 'The total sum of observable structural and functional properties of an organism'. Expressed by Hale \& Margham (1988) as resulting from, 'an interaction between the genotype and the environment in which development occurs'. Also by Merrell (1981, p.15), 'a genotype sets limits within which development can proceed. The particular phenotype to emerge is the result of the interaction between the genotype and the particular set of environmental conditions ....' In this sense all individuals are 'ecophenotypes'.

Ecophenotype - 'A phenotype exhibiting non-genetic adaptation associated with a given habitat, or to a given environmental factor'. This is close to the definition given by Mayr, Linsley \& Usinger (1953) which stresses 'specific ecological conditions'. Note, however, Merrell's remark (1981, p.74, line 13), 'it is well to remember that just about any phenotypic trait has both an environmental and a genetic component'. This point was also made by Ford (1975, p.385-386) concerning 'phenotypic and genetic plasticity, in Aglais urticae, the Small Tortoise-shell butterfly which exhibits colour changes according to the temperature in which the larvae are reared. He describes this as partly genetic and which by a process of 'genetic assimilation' (Waddington, 1953) becomes selected to provide a seasonal switch-control in other species.

Genetic Polymorphism (introduced by Ford, 1940) - 'The co-existence of two or more discontinuous, genetically determined, segregating forms in a population, where the frequency of the rarest type is not maintained by mutation alone'. In 1971, Ford specifically excluded subspecies and made it clear he regarded it as an intra-population phenomenon (i.e. intra-ecotypic) maintained in the case of balanced polymorphism' by balancing selection; described (1975, p.391, second para. line 7) as 'maintained by contending advantages and disadvantages in equilibrium. Yet here again, swift adaptations to changing conditions are possible, since the 
opposed selective forces are generally great'. The term 'transient polymorphism' was applied to an evolving population in which a mutant gene gradually replaces the normal allele.

Ecotype (introduced by Turesson, 1922) - A locally adapted population; a race or infraspecific group having distinctive characters which result from the selective pressures of the local environment; ecological race'. This term is most commonly applied to plants, in which variation is often discontinuous, and is considered infra-subspecific. An excellent example of adjacent ecotypes of tolerant and intolerant grasses maintained by a strong selection gradient over distances as small as 50-100 metres is described from heavy metal, mine waste and nearby pasture in North Wales. (Jain \& Bradshaw, 1966).

Cline (introduced by Huxley, 1939) - 'A character gradient; continuous variation in the expression of a character through a series of contiguous populations'. This is rather too generalised and misses the essential element from Huxley's definition which emphasises that clines represent variation in morphological and genetic traits caused by geographical variation in selection (see Levinton, 1988 p.125-127). Merrill (1981, p.287) notes that clines represent continuous variation, rather than the discontinuous variation of ecotypes, with gene-flow tending to smooth out the discontinuities, but also that they may be stepped. He also makes the important point (p.288) that a cline refers to a gradient in a single character which may cut across the natural populations. 'Thus clines have not been particularly useful in taxonomy: rather they are useful abstractions for dealing with geographical variation in individual traits'.

Clone - 'An assemblage of genetically identical organisms derived by asexual or vegetative multiplication from a single sexually derived individual'. Note that John Lee (pers. comm.) considers the definition of the term as presently used should stopafter "vegetative multiplication". Many micro-organisms propagate asexually for generations without an intervening sexual generation. This is true for most prokaryotes and many protists, including well-documented apogamic foraminiferal species'.

\section{Manuscript received December 1991}

Revised Manuscript accepted January 1992

\section{REFERENCES}

Boltovskoy, E. 1965. Twilight of foraminiferology. Journal of Paleontology, 39, 383-390.

Bradshaw, J.S. 1957. Laboratory studies on the rate of growth of the foraminifera, "Streblusbeccarii (Linné), var.tepida (Cushman)'. Journal of Palaeontology, 31 (6), 1138-1147.

Bradshaw, J.S. 1961. Laboratory experiments on the ecology of foraminifera. Contributions from the Cushman Foundation for Foraminiferal Research,.12, 87-106.

Desmond, A. \& Moore, J. 1991. Darwin. XXI + 5-808pp. Michael Joseph, London.

Feyling-Hanssen, R.W. 1972. The foraminifera Elphidium excavatum (Terquem) and its variant forms. Micropaleontology, 18 (3), 337-354.

Ford, E.B. 1940. Genetic research in the Lepidoptera. Annals of Eugenics, 10, 227-252.

Ford, E.B. 1971. Ecological Genetics. 3rd Ed. XX +410pp. Chapman \& Hall Ltd, London.

Ford, E.B. 1975. Ecological Genetics, 4th Ed. XX + 442pp. Chapman \& Hall Ltd, London.

Grell, K.G. 1973. Protozoology. 554pp. Springer-Verlag, Berlin, New York.
Hale, W.G. \& Margham, J.P. 1988. Dictionary of Biology. 565pp. Collins, London.

Hansen, H.J. \& Lykke-Anderson, A.-L. 1976. Wall structure and classification of fossil and Recent elphidiid and nonionid foraminifera. Fossils and Strata, 10, 1-37.

Haynes, J.R. 1973. Cardigan Bay Recent Forminifera. Bulletin of the British Museum of Natural History (Zoology), 4, 1-145.

Haynes, J.R. 1981. Foraminifera. 433pp. Macmillan, London and Basingstoke.

Haynes, J.R. \& Whittaker, J.E. 1990. The status of Rotalia Lamarck (Foraminifera) and the Rotaliidae Ehrenberg. Journal of Micropalaeontology, 9 (1), 95-106.

Huxley, J.S. 1939. Clines: an auxiliary method in taxonomy. Bijdragen tot de dierkunde, 27, 491-520.

Jain, S.K. \& Bradshaw, A.D. 1966. Evolutionary divergence among adjacent plant populations. 1. The evidence and its theoretical analysis. Heredity, 21, 42-144.

Johannsen, W. 1909. Elemente der exaten Erblichkeitslehre. VI + 516pp. Gustav Fischer, Jena.

Johnson, A.A. 1981. Detection of ecophenotypic variation in fossils and its application to a Jurassic scallop. Lethaia, 14, 277-285.

Levinton, J. 1988. Genetics, Paleontology and Macroevolution. 637pp. Cambridge University Press, Cambridge.

Lincoln, R.J. \& Boxshall, G.A. 1987. The Cambridge Illustrated Dictionary of Natural History. 413pp. Cambridge University Press, Cambridge.

Mayr, E., Linsley, E.G. \& Usinger, R.L. 1953. Methods and principles of systematic Zoology. 328pp. McGraw-Hill Book Co., New York.

Merrell, D.J. 1981. Ecological Genetics. 500pp. Longman, London.

Miller, A.A.L., Scott, D.B. \& Medioli, F.S. 1982. Elphidium excavatum (Terquem): Ecophenotypic versus subspecific variation. Journal of Foraminiferal Research, 12 (2), 116-144.

Moguilevsky, A., 1990. Cytogenetic studies on marine myocopid ostracoda: the karyotypes of some species of Vargula Skogsberg, 1920. p.187-208 In: Ostracoda and Global Events. Eds Whatley, R. \& Maybury, C. 621pp. Chapman \& Hall, London.

Murray, J.W. 1991. Ecology and Palaeoecology of benthic Foraminifera. 397 pp. Longman, Harwell, England, Wiley, New York.

Parker, F.L. 1962. Planktonic foraminiferal species in Pacific Sediments. Micropaleontology, 8 (2), 219-254.

Poag, C.W. 1978. Paired foraminiferal ecophenotypes in Gulf Coast estuaries: ecological and paleoecological implications. Transactions - Gulf Coast Association of Geological Societies, 28, 395-421.

Robbins, L.L. \& Healy-Williams, N. 1991. Toward a classification of planktonic foraminifera based on biochemical, geochemical and morphological criteria. Journal of Fornminiferal Research, 21 (2), 159-167.

Schnitker, D. 1974. Ecotypic variation in Ammonia beccarii (Linné). Journal of Foraminiferal Research, 4 (4), 216-223.

Selander, R.K. \& Kaufman, D.W. 1973. Genic variability and strategies of adaptation in animals. Proceedings of the National Academy of Science, 70, 1875-1877.

Turesson, G. 1922. The species and the variety as ecological units. Hereditas, 3, 100-113.

Waddington, C.H.1953. Genetic assimilation of an acquired character. Evolution, 7, 118-126.

Walton, W.R. \& Sloan, B.J. 1990. The genus Ammonia Brunnich: its geographical distribution and morphologic variability. Journal of Foraminiferal Research, 20 (2), 128-156.

Ward, R.D. \& Galleguillos, R.A. 1978. Protein variation in the Plaice, Dab and Flounder, and their genetic relationships. pp.71-73 Im: Battaglia, B. \& Beardmore, J.A. (Eds) Marine organisms, genetics, ecology and evolution. 757pp. Plenum Press, New York and London.

Wilkinson, I.P. 1979. The taxonomy, morphology and distribution of the Quaternary and Recent foraminifer Elphtidium clavatum Cushman. Journal of Paleontology, 53 (3), 628-716. 